\title{
Bisphosphonates and mortality: confounding in observational studies?
}

\author{
J. Bergman ${ }^{1}$ - A. Nordström ${ }^{2,3}$ - A. Hommel ${ }^{4}$ - M. Kivipelto ${ }^{5,6,7}$ • P. Nordström ${ }^{1}$
}

Received: 8 February 2019 / Accepted: 15 July 2019 / Published online: 31 July 2019

(C) The Author(s) 2019

\begin{abstract}
Summary Numerous observational studies suggest that bisphosphonates reduce mortality. This study showed that bisphosphonate use is associated with lower mortality within days of treatment, although the association was not significant until the second week. Such an early association is consistent with confounding, although an early treatment effect cannot be ruled out.

Introduction The purpose of this study was to examine whether confounding explains why numerous observational studies show that bisphosphonate use is associated with lower mortality. To this end, we examined how soon after treatment initiation a lower mortality rate can be observed. We hypothesized that, due to confounding, the association would be observed immediately.

Methods This was a retrospective cohort study of hip fracture patients discharged from Swedish hospitals between 1 July 2006 and 31 December 2015. The data covered 260,574 hip fracture patients and were obtained from the Swedish Hip Fracture Register and national registers. Of the 260,574 patients, 49,765 met all eligibility criteria and 10,178 were pair matched (bisphosphonate users to controls) using time-dependent propensity scores. The matching variables were age, sex, diagnoses, prescription medications, type of hip fracture, type of surgical procedure, known or suspected dementia, and physical functioning status.

Results Over a median follow-up of 2.8 years, 2922 of the 10,178 matched patients died. The mortality rate was 7.9 deaths per 100 person-years in bisphosphonate users and 9.4 deaths in controls, which corresponded to a $15 \%$ lower mortality rate in bisphosphonate users (hazard ratio $0.85,95 \%$ confidence interval $0.79-0.91$ ). The risk of death was lower in bisphosphonate users from day 6 of treatment, although the association was not significant until the second week.

Conclusion Bisphosphonate use was associated with lower mortality within days of treatment initiation. This finding is consistent with confounding, although an early treatment effect cannot be ruled out.
\end{abstract}

Keywords Bisphosphonates $\cdot$ Death $\cdot$ Mortality $\cdot$ Observational study $\cdot$ Osteoporosis

\section{Introduction}

Bisphosphonates, inhibitors of bone resorption, are primarily used in osteoporosis patients to reduce fracture rates [1], but some research suggests that bisphosphonates also reduce mortality rates. In a randomized controlled trial, Lyles et al. reported that the intravenous bisphosphonate zoledronic acid significantly reduced mortality by $28 \%$ in hip fracture patients [2]. Such

Electronic supplementary material The online version of this article (https://doi.org/10.1007/s00198-019-05097-1) contains supplementary material, which is available to authorized users.

P. Nordström

peter.nordstrom@umu.se

1 Unit of Geriatric Medicine, Department of Community Medicine and Rehabilitation, Umeå University, 90187 Umeå, Sweden

2 Section of Sustainable Health, Department of Public Health and Clinical Medicine, Umeå University, 90187 Umeå, Sweden

3 School of Sport Sciences, UiT Arctic University of Norway, Postboks 1621, 9509 Alta, Norway
4 Department of Care Sciences, Malmö University, 20506 Malmö, Sweden

5 Division of Clinical geriatrics, Department of Neurobiology, Care Sciences and Society, Karolinska Institutet, Plan 7, 14183 Huddinge, Sweden

6 Theme Aging, Karolinska Univeristy Hospital, 14186 Stockholm, Sweden

7 Research and Development Unit, Stockholm Sjukhem, Mariebergsgatan 22, 11219 Stockholm, Sweden 
an effect was not, however, detected in other trials of zoledronic acid or other bisphosphonates [3-8]. Although one metaanalysis did detect a significant effect of bisphosphonates on mortality [9], another meta-analysis did not [10].

In contrast to the uncertain evidence provided by randomized controlled trials, numerous observational studies show that bisphosphonate use is associated with lower mortality [11, 12, 21, 22, 13-20]. These results could be confirmation that bisphosphonates indeed have a beneficial effect on mortality. However, observational studies are susceptible to confounding [23], so these results could also be a reflection of better overall health in bisphosphonate-treated patients than in non-treated patients. In one study, Bondo et al. concluded that confounding is likely because they found a lower mortality rate in patients who had received only one prescription for a bisphosphonate ( $\leq 84$ days of treatment) [24]; they reasoned that such an early treatment effect is unlikely. In another study, Sing et al. reasoned that a treatment effect within 30 days would be unlikely, so they excluded patients with $<30$ days of treatment in a sensitivity analysis [12]. Because bisphosphonate use was still associated with lower mortality after this exclusion, the authors concluded that confounding was unlikely. However, this analysis would not eliminate confounding in patients with $\geq 30$ days of treatment, so a better approach would have been to examine whether there was an association in the first 30 days of treatment, when no effect was expected.

To examine further the possibility of confounding, we aimed to clarify how soon after initiation of bisphosphonate treatment a lower mortality rate can be observed. We hypothesized that, due to confounding, the association would be observed immediately. We tested this hypothesis in a retrospective cohort study of Swedish hip fracture patients.

\section{Methods}

\section{Data sources}

Hip fracture patients were identified through the Swedish Hip Fracture Register. This database was created in 1988 to improve the quality of care after hip fractures in Sweden, and it covers an estimated $87 \%$ of hip fracture patients in the country $[25,26]$. The data are collected from hospital wards using standardized forms, which are filled out by a health care professional, usually a nurse [26]. Available variables that were used in this study include type of fracture, type of surgical procedure, housing situation (e.g., private home or nursing home), mental functioning status (e.g., known or suspected dementia), and physical functioning status (e.g., walking ability before fracture, use of walking aid before fracture, and American Society of Anesthesiologists [ASA] Physical Status Score]).
We collected medical data about the hip fracture patients from the National Patient Register and the Swedish Cancer Register. The National Patient Register is a database of inpatient admissions and specialist (non-primary care) outpatient visits [27]. All public and private healthcare providers in Sweden have been required to report inpatient admissions since 1987 and specialist outpatient visits since 2001. Variables available in the National Patient Register include a primary diagnosis, secondary diagnoses, and the date of the visit or the dates of admission and discharge. Diagnoses have been coded according to the 10th revision of the International Classification of Diseases (ICD-10) since 1997 and according to earlier revisions prior to this year. The Swedish Cancer Registry is a database of cancer diagnoses, coded according to the ICD. All health care providers have been required to report new cases of cancer to this registry since 1958 [28].

We obtained data about prescription medication use from the Prescribed Drug Register, which contains information about prescription medications dispensed at pharmacies in Sweden since July 2005 [29]. Available variables include Anatomical Therapeutic Chemical (ATC) code, pack size, number of packs dispensed, and date of dispensation.

We collected mortality data from the Cause of Death Register, which records the date and cause of death of residents of Sweden since 1961 [30]. The cause of death is determined by the physician who verified the death, and it is coded according to the ICD-10.

We obtained emigration data from the Register of the Total Population. This and the abovementioned databases were linked using personal identity numbers, which are issued by the Swedish Tax Agency to residents of Sweden upon birth or immigration. These numbers are unique, although they are occasionally reused if a person immigrating to Sweden has the same date of birth as a deceased person. For privacy reasons, we received data files in which each personal identity number had been replaced by a random identifier, generated by Statistics Sweden.

The present study was approved by the Regional Ethical Review Board in Umeå, Sweden (Dnr 2013-86-31M, 2013$304-32 \mathrm{M})$. The review board waived the requirement of obtaining informed consent.

\section{Study design}

In this analysis, we included hip fracture patients who were discharged alive from 1 July 2006 to 31 December 2015 (the accrual period). Patients who sustained more than one hip fracture during this period were included from the date of discharge following their first hip fracture. Patients were excluded if their latest personal identity number was unavailable, if they had a reused personal identity number, or if they had missing data about a confounder obtained from the Swedish Hip Fracture Register (referred to as hospitalization data). 
To reduce confounding in observational studies, the epidemiology literature has recommended researchers to imitate the eligibility criteria of randomized controlled trials [31, 32]. Therefore, we imitated the eligibility criteria of the trial by Lyles et al., which reported that a bisphosphonate significantly reduced mortality [2]. We did this by excluding subjects for the following reasons: age $<50$ years; dispensation of bisphosphonate in the last year; radiotherapy or diagnosis of cancer in the last 5 years; diagnosis of chronic kidney disease, solid organ transplantation, hypercalcemia, hyperparathyroidism, or metabolic bone disease other than osteoporosis (osteogenesis imperfecta, osteomalacia, or Paget's disease of bone); prior use of parathyroid hormone or strontium ranelate; use of systemic corticosteroids in the last 6 months; pathologic hip fracture; immobility prior to hip fracture; and limited life expectancy (defined here as ASA Physical Status Score $\geq 4$ ). Classification codes for the mentioned diagnoses and medications are available in Supplemental Table 1 . We did not have access to variables to exclude for high-trauma hip fracture, inability or unwillingness to take oral bisphosphonates, allergy to bisphosphonates, uveitis, iritis, tibolone or sodium fluoride use, pregnancy, or high level of serum alkaline phosphatase [2].

Subjects were classified as bisphosphonate users from the date they were first dispensed a bisphosphonate. They remained in the bisphosphonate group for the duration of follow-up, as our aim was not to examine the effect of adherence or persistence.

The main study outcome was all-cause mortality. Secondary outcomes were death from one of the following causes: cardiovascular disease; cerebrovascular disease; respiratory disease; dementia, Alzheimer's disease, or senility; neoplasm; and injury from accident. ICD-10 codes for these causes are available in Supplemental Table 1.

The confounders we considered and controlled for are listed in Table 1. The confounders were selected because they were used in a post-hoc analysis of the trial by Lyles et al. [33], in previous observational studies of bisphosphonates and mortality [12, 13, 22, 14-21], or in FRAX, a common fracture risk assessment tool. Classification codes for medications and diagnoses are available in Supplemental Table 1.

\section{Statistical analysis}

The eligible cohort was followed from date of discharge until death, emigration, or 31 December 2016 (whichever came first). Bisphosphonate users accrued follow-up time to the nonuser group until the date when they were first dispensed a bisphosphonate. Hazard ratios were calculated using Cox regression, a model in which bisphosphonate use and confounders were coded as time-varying variables.
To examine the effect of bisphosphonates as a function of treatment duration, it was necessary to change the start of follow-up from date of discharge to date of treatment initiation. Therefore, our main analysis was not the analysis of the full eligible cohort but an analysis of a matched sub-cohort, in which bisphosphonate users were followed from the date they were first dispensed a bisphosphonate and matched controls were followed from a comparable baseline date. This baseline date was the date (post hip fracture) that occurred after the same number of days as treatment initiation did in the corresponding bisphosphonate user.

The matching method we used was time-dependent propensity score matching, which enables propensity-score matching when treatment is time varying [34, 35]. It involves matching a patient who receives treatment at a particular time to a patient who has not received treatment by that same time, but who perhaps later received treatment. In our case, time was counted as days since hospital discharge. By including later-treated patients in the control group, time-dependent propensity score matching prevents the control group from consisting solely of patients who are never considered for treatment and who therefore are likely to be healthier than treated patients [34]. It also prevents immortal-time bias [36].

Propensity scores were estimated using Cox regression with the variables listed in Table 1. The matching algorithm was one-to-one nearest neighbor (psmatch 2 program in Stata). We used a caliper of $20 \%$ of the standard deviation of propensity scores. Confounder balance was assessed using standardized mean differences; differences of $<0.1$ were considered negligible [37].

In the analysis of the matched cohort, confidence intervals for hazard ratios were estimated using robust standard errors [38]. The proportional hazards assumption was not assessed. Instead, we examined whether the relative risk of death changed over time by plotting the ratio of the Kaplan-Meier curve for bisphosphonate users to that for controls [39]. Pointwise confidence intervals were obtained using the bootstrap percentile method [39], based on 1000 bootstrap replicates. To take account of the matching, we bootstrap sampled matched pairs instead of individual subjects.

A subgroup analysis was conducted by type of bisphosphonate. In this analysis, bisphosphonate users were censored upon dispensation of a different bisphosphonate. Two sensitivity analyses were performed. First, subjects were excluded or censored if they received an osteoporosis medication other than a bisphosphonate. Second, analyses were rerun including only subjects discharged to a private home, as osteoporosis medications taken in nursing homes and other institutions may be underreported in the Prescribed Drug Register [29].

Missing days of the month were imputed as the first of the month. Missing months were imputed as January. Missing years were imputed as the start the study period (1 July 2006). All statistical analyses were performed in Stata 
Table 1 Baseline characteristics

Matched cohort

\begin{tabular}{|c|c|c|c|c|}
\hline \multirow{2}{*}{ Variable } & \multirow[b]{2}{*}{ Eligible cohort } & \\
\hline & & $\mathrm{BP}$ & Control & SMD \\
\hline$N$ & 49,765 & 5089 & 5089 & - \\
\hline Age, mean (SD), years & $81(9)$ & $76(8)$ & $76(9)$ & 0.01 \\
\hline Female sex, $n(\%)$ & $34,844(70.0)$ & $4145(81.5)$ & $4121(81.0)$ & 0.01 \\
\hline Months between discharge and baseline, median (IQR) & - & $5(2-13)$ & $5(2-13)$ & - \\
\hline \multicolumn{5}{|l|}{ Hospitalization data } \\
\hline Days of hospital stay, mean (SD) & $9(6)$ & $8(5)$ & $8(5)$ & 0.00 \\
\hline \multicolumn{5}{|l|}{ Type of hip fracture, $n(\%)$} \\
\hline Cervical & $27,594(55.5)$ & $2886(56.7)$ & $2805(55.1)$ & 0.03 \\
\hline Intertrochanteric & $18,411(37.0)$ & $1823(35.8)$ & $1929(37.9)$ & 0.04 \\
\hline Subtrochanteric & $3760(7.6)$ & $380(7.5)$ & $355(7.0)$ & 0.02 \\
\hline Admitted from private home, $n(\%)$ & $36,472(73.3)$ & $4709(92.5)$ & $4730(93.0)$ & 0.02 \\
\hline Discharged to private home, $n(\%)$ & $17,130(34.4)$ & $2739(53.8)$ & $2734(53.7)$ & 0.00 \\
\hline Known/suspected dementia, $n(\%)$ & $16,110(32.4)$ & $519(10.2)$ & $482(9.5)$ & 0.02 \\
\hline Walking aid before fracture, $n(\%)$ & $24,800(49.8)$ & $1625(31.9)$ & $1529(30.1)$ & 0.04 \\
\hline \multicolumn{5}{|l|}{ Walking ability before fracture, $n(\%)$} \\
\hline Walked outdoors alone & $32,077(64.5)$ & $4382(86.1)$ & $4410(86.7)$ & 0.02 \\
\hline Walked outdoors with company & $4035(8.1)$ & $208(4.1)$ & $202(4.0)$ & 0.01 \\
\hline Walked indoors alone & $10,824(21.8)$ & $430(8.5)$ & $412(8.1)$ & 0.01 \\
\hline Walked indoors with company & $2829(5.7)$ & $69(1.4)$ & $65(1.3)$ & 0.01 \\
\hline \multicolumn{5}{|l|}{ ASA physical status score, $n(\%)$} \\
\hline 1 & $4486(9.0)$ & $769(15.1)$ & $730(14.3)$ & 0.02 \\
\hline 2 & $22,423(45.1)$ & $2757(54.2)$ & $2841(55.8)$ & 0.03 \\
\hline 3 & $22,856(45.9)$ & $1563(30.7)$ & $1518(29.8)$ & 0.02 \\
\hline \multicolumn{5}{|l|}{ Diagnoses, $n(\%)$} \\
\hline Angina pectoris & $7078(14.2)$ & $551(10.8)$ & $545(10.7)$ & 0.00 \\
\hline Arteriosclerosis & $1597(3.2)$ & $147(2.9)$ & $162(3.2)$ & 0.02 \\
\hline Atrial fibrillation/flutter & $9558(19.2)$ & $774(15.2)$ & $760(14.9)$ & 0.01 \\
\hline COPD & $1029(2.1)$ & $139(2.7)$ & $139(2.7)$ & 0 \\
\hline Diabetes mellitus & $7094(14.3)$ & $681(13.4)$ & $705(13.9)$ & 0.01 \\
\hline Non-hip fracture in the last 5 years & $9957(20.0)$ & $1098(21.6)$ & $1072(21.1)$ & 0.01 \\
\hline Heart failure & $6932(13.9)$ & $495(9.7)$ & $469(9.2)$ & 0.02 \\
\hline Hypercholesterolemia/hyperlipidemia & $4260(8.6)$ & $554(10.9)$ & $585(11.5)$ & 0.02 \\
\hline Acute renal failure & $560(1.1)$ & $51(1.0)$ & $47(0.9)$ & 0.01 \\
\hline Mental/behavioral disorder due to alcohol use & $2545(5.1)$ & $282(5.5)$ & $286(5.6)$ & 0.00 \\
\hline Myocardial infarction & $4940(9.9)$ & $332(6.5)$ & $313(6.2)$ & 0.02 \\
\hline Osteoporosis & $4545(9.1)$ & $1325(26.0)$ & $1344(26.4)$ & 0.01 \\
\hline Rheumatoid arthritis & $759(1.5)$ & $130(2.6)$ & $118(2.3)$ & 0.02 \\
\hline Stroke & $7447(15.0)$ & $594(11.7)$ & $590(11.6)$ & 0.00 \\
\hline \multicolumn{5}{|l|}{ Medications, $n(\%)$} \\
\hline Antidiabetic agents & $6164(12.4)$ & $600(11.8)$ & $630(12.4)$ & 0.02 \\
\hline Antithrombotic agents & $31,971(64.2)$ & $3682(72.4)$ & $3685(72.4)$ & 0.00 \\
\hline Lipid-lowering agents & $13,856(27.8)$ & $1720(33.8)$ & $1752(34.4)$ & 0.01 \\
\hline Calcium/vitamin D & $10,247(20.6)$ & $4617(90.7)$ & $4593(90.3)$ & 0.02 \\
\hline Denosumab & $66(0.1)$ & $6(0.1)$ & $3(0.1)$ & 0.02 \\
\hline Raloxifene & $159(0.3)$ & $27(0.5)$ & $36(0.7)$ & 0.02 \\
\hline
\end{tabular}

$B P$ bisphosphonate, $S M D$ standardized mean difference, $A S A$ American Society of Anesthesiologists, $C O P D$ chronic obstructive pulmonary disease 
(version 15) and R (version 3.5.3), with the Rstudio interface. We did not have a pre-specified analysis plan.

\section{Results}

\section{Eligible cohort and matched cohort}

Data were available for 260,574 hip fracture patients, of whom 49,765 met all eligibility criteria (Fig. 1). Bisphosphonates were dispensed to $12 \%(n=6043)$ of this eligible cohort during follow-up, a median of 2.8 years (mean 3.3 years). Matching resulted in a sub-cohort of 5089 bisphosphonate users and 5089 controls with similar baseline characteristics (Table 1). Compared to the average hip fracture patient in the eligible cohort, matched bisphosphonate users were younger, more often female, had a better physical functioning status, more often lived in a private home, had diagnosed osteoporosis, and received prescription calcium and/or vitamin D, and less often had dementia or cardiovascular disease. However, bisphosphonate users had more often received antithrombotic or lipid-lowering agents (Table 1).

In the matched cohort, the most commonly dispensed bisphosphonates were alendronate (92\%, $n=4689)$, risedronate $(4 \%, n=221)$, and zoledronic acid $(3 \%, n=$
161). Seventeen percent ( $n=882)$ of matched controls started bisphosphonate treatment during follow-up. Five percent ( $n=$ 232) of matched bisphosphonate users switched to a different bisphosphonate during follow-up. The median follow-up was 2.8 years (mean 3.3 years).

\section{Mortality}

Table 2 provides mortality rates and hazard ratios for the full eligible cohort and for the matched cohort. In the full cohort, bisphosphonate use was associated with a 55\% lower mortality rate before adjustment for confounders (hazard ratio [HR] $0.45,95 \%$ confidence interval $[\mathrm{CI}] 0.43-0.48)$. After adjustment for confounders, the association weakened but remained (fully-adjusted HR $0.85,95 \%$ CI $0.80-0.90)$. A similar association was observed in the matched cohort (HR $0.85,95 \% \mathrm{CI}$ 0.79-0.91).

The analysis of the matched cohort showed that the association between alendronate use and mortality was similar to the association between risedronate use and mortality (Table 2). Use of zoledronic acid, however, was associated with higher mortality (Table 2). Bisphosphonate use was associated with a lower or similar rate of mortality due to specific causes (Table 3 ).

Fig. 1 Cohort selection

Excluded $(\mathrm{n}=\mathbf{2 1 0}, \mathbf{8 0 9})$ :

- 7 unavailable personal identity number

- 152 reused personal identity number

- 1412 missing date of hospital discharge

135,219 discharged outside of accrual period

44,982 missing data about confounder (hospitalization data)

2669 discharged dead

964 age $<50$ years upon discharge

4716 bisphosphonate dispensation in the last 12 months

6901 cancer or radiotherapy in the last 5 years

2751 chronic kidney disease

6 solid organ transplantation

126 hypercalcemia

558 metabolic bone disease other than osteoporosis

137 use of parathyroid hormone or strontium ranelate

4158 systemic corticosteroid use in the last 6 months

732 pathologic hip fracture

1960 immobile prior to hip fracture

3359 limited life expectancy (ASA Phyical Status score $\geq 4$ )

49,765 eligible

10,178 matched 
Table 2 Bisphosphonate use and mortality

Incidence rate/100 person-years (number of deaths)

\begin{tabular}{|c|c|c|c|c|}
\hline Cohort & $\mathrm{BP}$ & Control & $\mathrm{HR}(95 \% \mathrm{CI})$ & $P$ \\
\hline \multicolumn{5}{|l|}{ Entire eligible cohort } \\
\hline Unadjusted & $7.5(1460)$ & $17.5(24962)$ & $0.45(0.43-0.48)$ & $<0.001$ \\
\hline Adjusted for age and sex & & & $0.66(0.62-0.70)$ & $<0.001$ \\
\hline Adjusted for age, sex, medications and diagnoses & & & $0.70(0.66-0.74)$ & $<0.001$ \\
\hline $\begin{array}{l}\text { Adjusted for age, sex, medications, diagnoses, length } \\
\text { of hospitalization, type of hip fracture, known/suspected } \\
\text { dementia, and physical functioning status* }\end{array}$ & & & $0.85(0.80-0.90)$ & $<0.001$ \\
\hline \multicolumn{5}{|l|}{ Matched cohort } \\
\hline Total & $7.9(1313)$ & $9.4(1609)$ & $0.85(0.79-0.91)$ & $<0.001$ \\
\hline Alendronate & $7.7(1167)$ & $9.5(1486)$ & $0.82(0.76-0.89)$ & $<0.001$ \\
\hline Risedronate & $8.3(83)$ & $9.4(69)$ & $0.84(0.61-1.15)$ & 0.27 \\
\hline Zoledronic acid & $11.2(48)$ & $7.7(45)$ & $1.51(1.00-2.28)$ & 0.048 \\
\hline
\end{tabular}

$B P$ bisphosphonate, $H R$ hazard ratio, $C I$ confidence interval

*Physical functioning status includes the following variables: admitted from private home, discharged to private home, use of walking aid before fracture, walking ability before fracture, and American Society of Anesthesiologists physical status score

For the matched cohort, Fig. 2 displays Kaplan-Meier curves and the ratio of these curves (the relative risk of death) over 3 years of follow-up. As shown, the risk of death was lower in bisphosphonate users early after treatment initiation, although there was an initially increased risk. Figure 3 shows that the initial increase was based on $<5$ cases in bisphosphonate users and $<4$ cases in controls. Furthermore, the risk was lower in bisphosphonate users from day 6 of treatment, although the association was not significant until the second week because the confidence interval for the relative risk overlapped 1 until this time (Fig. 3). Both in Fig. 2 and Fig. 3, the confidence intervals are plotted from day 6 because the small number of deaths prior to this day led to undefined estimates of relative risk in some bootstrap replicates (that is, when the risk of death was $0 \%$ in the control group, the denominator).

\section{Sensitivity analyses}

The association between bisphosphonate use and mortality did not change substantially when we excluded and censored patients who used an osteoporosis medication other than a bisphosphonate (HR 0.84 in the matched cohort, 95\% CI 0.78-90). Similarly, the association did not change substantially when we included only patients discharged to a private home (HR 0.81 in the matched cohort, 95\% CI 0.72-0.91).
Table 3 Bisphosphonate use and cause-specific mortality in the matched cohort

\begin{tabular}{|c|c|c|c|c|}
\hline \multirow[b]{2}{*}{ Cause } & \multicolumn{2}{|c|}{ Number $(\%)$ of deaths } & \multirow[b]{2}{*}{ HR $(95 \% \mathrm{CI})$} & \multirow[b]{2}{*}{$P$} \\
\hline & $\mathrm{BP}$ & Control & & \\
\hline All causes & $1313(100)$ & $1609(100)$ & $0.85(0.79-0.91)$ & $<0.001$ \\
\hline Cardiovascular & $422(32.1)$ & $505(31.4)$ & $0.87(0.76-0.99)$ & 0.03 \\
\hline Arrhythmia & 55 & 79 & $0.72(0.51-1.01)$ & 0.06 \\
\hline Cerebrovascular & $123(9.4)$ & $157(9.8)$ & $0.82(0.64-1.03)$ & 0.09 \\
\hline Respiratory & $123(9.4)$ & $152(9.4)$ & $0.84(0.66-1.06)$ & 0.14 \\
\hline Pneumonia & 36 & 46 & $0.81(0.52-1.25)$ & 0.34 \\
\hline Dementia/Alzheimer's disease/senility & $169(12.9)$ & $239(14.9)$ & $0.74(0.61-0.90)$ & 0.003 \\
\hline Neoplasm & $219(16.7)$ & $233(14.5)$ & $0.97(0.80-1.16)$ & 0.73 \\
\hline Injury from accident & $40(3.0)$ & $54(3.4)$ & $0.76(0.51-1.15)$ & 0.20 \\
\hline Other & $208(15.8)$ & $254(15.8)$ & $0.85(0.71-1.02)$ & 0.08 \\
\hline Unspecified & $9(0.7)$ & $15(0.9)$ & $0.62(0.27-1.43)$ & 0.26 \\
\hline
\end{tabular}

$B P$ bisphosphonate, $H R$ hazard ratio, $C I$ confidence interval 


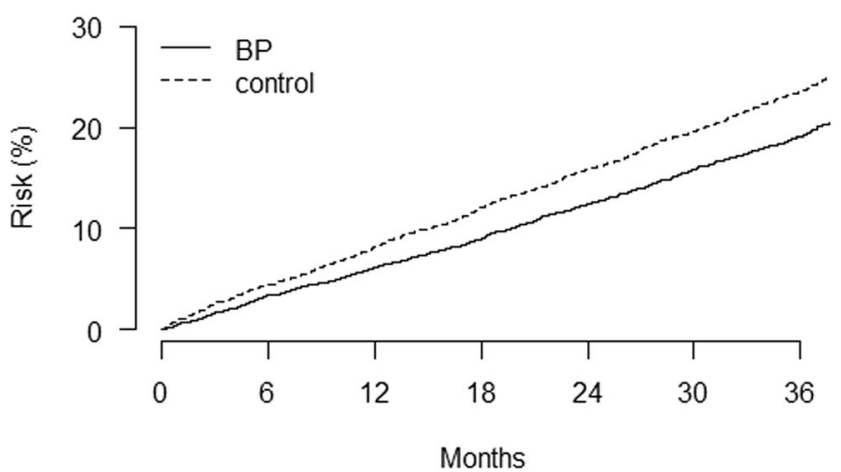

No. at risk

$\begin{array}{llllllll}\text { BP } & 5089 & 4748 & 4299 & 3799 & 3259 & 2836 & 2412 \\ \text { Control } & 5089 & 4713 & 4279 & 3762 & 3262 & 2860 & 2415\end{array}$

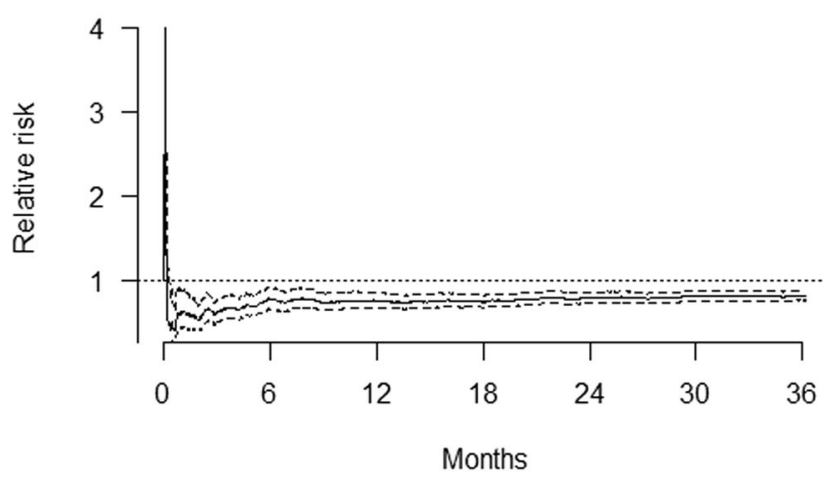

$\begin{array}{lrrrrrrc}\text { No. of deaths } & & & & & & \\ \text { BP } & 0 & 168 & 300 & 422 & 558 & 680 & 784 \\ \text { Control } & 0 & 220 & 401 & 577 & 727 & 867 & 1002\end{array}$

Fig. 2 Kaplan-Meier estimated risk and relative risk (bisphosphonate users versus controls) of death in the matched cohort during the first 3 years after initiation of bisphosphonate (BP) treatment. In the bottom panel, the solid line indicates relative risk and the dashed lines indicate $95 \%$ confidence intervals

\section{Discussion}

The results showed that bisphosphonate use was associated with lower mortality in hip fracture patients. The risk of death was lower in bisphosphonate users from day 6 of treatment, although the exact timing was unclear due to statistical uncertainty, resulting from an initially small number of deaths.

A lower mortality rate soon after treatment initiation is consistent with a confounded association, as confounding implies a difference between study groups at baseline. Confounding could have arisen for at least two reasons. First, physicians may be more likely to prescribe bisphosphonates to patients with a decent life expectancy. This explanation is supported by our data, as bisphosphonate users appeared to be in better general health than the average hip fracture patient was. A similar line of reasoning was used by Bondo et al., because they found a lower mortality rate in patients who had received only one prescription for a bisphosphonate ( $\leq 84$ days of treatment) [24]. Furthermore, this explanation is reasonable because life expectancy is
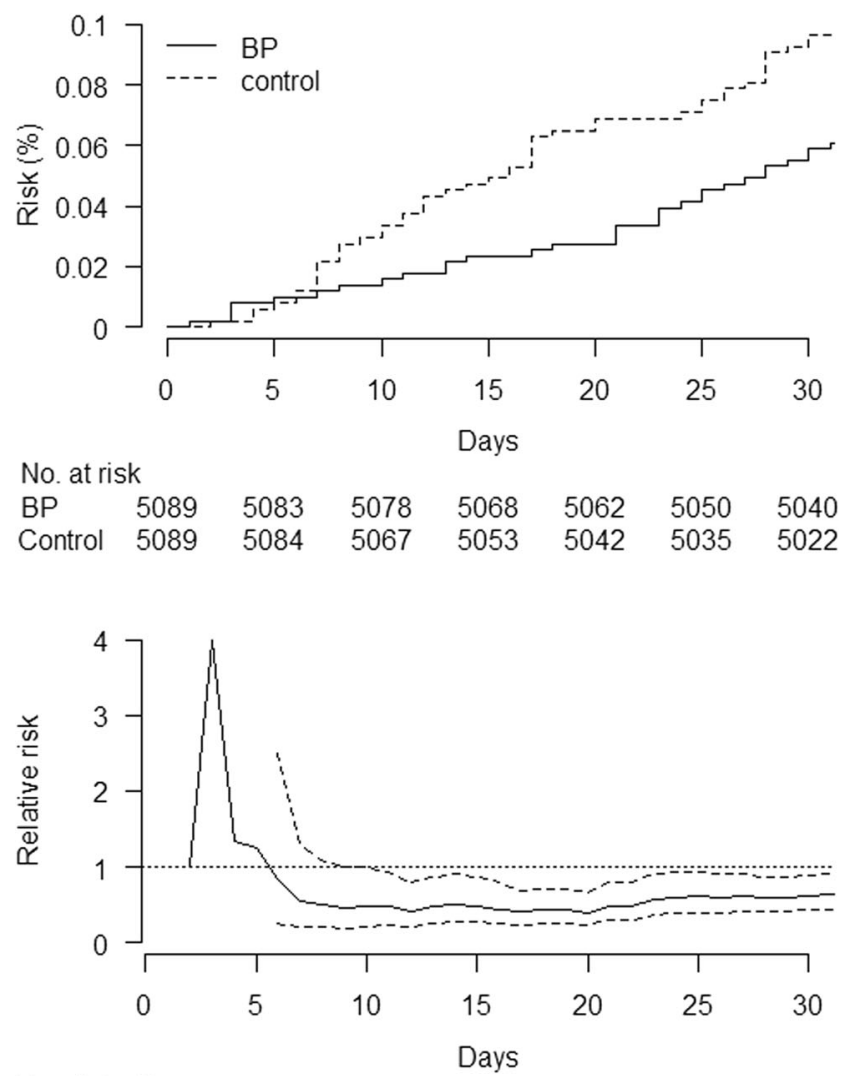

No. of deaths

$\begin{array}{lllccccc}\text { BP } & 0 & 5 & 8 & 12 & 14 & 23 & 30 \\ \text { Control } & 0 & 4 & 17 & 25 & 35 & 38 & 49\end{array}$

Fig. 3 Kaplan-Meier estimated risk and relative risk (bisphosphonate users versus controls) of death in the matched cohort during the first 30 days after initiation of bisphosphonate (BP) treatment. In the bottom panel, the solid line indicates relative risk and the dashed lines indicate $95 \%$ confidence intervals

incorporated into fracture risk assessment [40], because the anti-fracture effects of bisphosphonates may be delayed [41], and because physicians may be concerned about side effects in patients who are in poor health. Second, confounding could have arisen if healthier patients are more likely to collect their prescriptions. This explanation was not possible to assess in our study because we did not have data about uncollected prescriptions. Previous observational studies did not explore this second explanation either [11, 12, 21, 22, 13-20].

Although an association soon after treatment initiation is consistent with confounding, an early treatment effect cannot be ruled out. From a physiological perspective, it is unclear how soon bisphosphonates could begin to take effect on mortality. Proposed physiological mechanisms include anti-angiogenesis, slowing of atherosclerosis, improving general health status, strengthening the immune system, and preventing fractures [10,33]. However, even the most well documented of these effects of bisphosphonates, that of fracture reduction, has an unclear time to onset [41]. Despite this uncertainty, a randomized controlled trial by Lyles et al. suggested that the 
effect on mortality is delayed, as zoledronic acid was associated with significantly lower mortality but survival curves were similar until the second year of treatment [2]. A similarity of survival curves does not preclude an early effect, as randomized controlled trials often are underpowered to determine time to treatment effect [42]. However, it contradicts the findings of our study and those of most previous observational studies that reported survival curves, as these curves diverged early $[12,13,15,17,20]$. Two exceptions are one study that displayed survival curves only for death due to colon cancer [18] and another study that had a flawed analysis, which guaranteed survival in the control group for at least 90 days [19].

To clarify how early the association could be observed, we plotted the ratio of the survival curves over time, which showed that the association could be observed within days. This result cannot be directly compared to the results of previous studies, as these did not examine the association continuously over time. However, two previous studies in hip fracture patients divided follow-up into longer periods and showed that bisphosphonate use was associated with lower mortality within 3 months and within 12 months [11, 12]. These two studies in hip fracture patients, together with the abovementioned study by Bondo et al. [24], indicate that the early separation of survival curves seen in observational studies of hip fracture patients and non-hip fracture patients can be observed within months of treatment [12, $13,15,17,20]$. Our study adds to these data by showing that a lower mortality rate can be observed within days.

The results of our study could not be explained by a large number of confounders, including diagnoses, medications, known or suspected dementia, and physical functioning status. To control for these confounders, we used methods recommended by the epidemiology or statistics literature: imitating the exclusion criteria of a randomized controlled trial [31, 32], matching using time-dependent propensity scores [34, $35]$, and adjusting for time-fixed and time-varying confounders using regression [36, 43]. We also used methods to avoid bias, including analyzing bisphosphonate use as a timevarying variable to avoid immortal-time bias [36] and analyzing incident users of bisphosphonates to prevent bias by the inclusion of prevalent users [43]. Several of these strengths of our study were also mentioned as strengths of previous observational studies $[12,13,15,17,19,20]$. Although these strengths could mean that our results reflect a true treatment effect, our results could also be due to residual or unmeasured confounding. Residual and unmeasured confounding are difficult to rule out because doing so requires access to variables that accurately quantify why some patients receive bisphosphonates while others do not. Due to this difficulty, some researchers argue that it is rarely possible to reliably rule out confounding in observational studies of treatment effects [23]. Therefore, controlling for confounding was not our approach, but to assess the presence of confounding.
Although zoledronic acid was reported to reduce mortality in the randomized controlled trial by Lyles et al. [2], our subgroup analysis showed that the use of zoledronic acid was associated with higher mortality. This result could be due to chance, as the number of zoledronic acid users was small. It could also be due to confounding in the opposite direction (toward a harmful effect of bisphosphonates) because patients who receive zoledronic acid rather than oral bisphosphonates may in poorer health, as Swedish guidelines recommend zoledronic acid for patients who do not tolerate oral bisphosphonate or who are likely to be nonadherent [44].

The following limitations of this study should be noted. First, we included only hip fracture patients because we could obtain data with many confounders for this population and because bisphosphonate use has been consistently associated with lower mortality in hip fracture patients $[11,12,14,15$, $17,24]$. In other populations, confounding may be less strong or have a different effect due to different prescribing practices. This possibility could explain why bisphosphonates have not always been associated with lower mortality in other populations, such as cancer patients [21,45]. Second, we did not have access to all confounders included in previous studies. However, this limitation is unlikely to explain our results because, as mentioned, our results are consistent with those of most previous studies. Third, because of limited statistical power, it was not possible to determine whether the risk is of death differed between bisphosphonate users and nonusers immediately after treatment initiation (that is, from day 1 ).

In sum, our study adds to the findings of previous observational studies by showing that the association of bisphosphonate use with lower mortality can be observed within days, not just within months, of treatment. Although such an early treatment effect cannot be ruled out due to limited evidence, it is consistent with confounding. This uncertainty implies that our results should not be interpreted as evidence that bisphosphonates have a beneficial effect on mortality, even though we avoided certain biases and controlled for a large number of confounders. Since most previous observational studies also showed that the association begins early, these results may also be confounded. Therefore, they should be interpreted with caution. Future studies that examine the presence of confounding could compare associations in patients who are prescribed a bisphosphonate but who either do or do not collect their prescriptions. This approach may clarify whether results could be confounded because healthier patients are more likely to collect their prescriptions or because physicians' are more likely to prescribe bisphosphonates to healthier patients. Future observational studies that examine the effect of bisphosphonates on mortality should explain why confounding was reliably eliminated. 
Funding Information Open access funding provided by Umea University. This study was funded by Vetenskapsrådet (grant number 2016-02584), Stockholms Sjukhem, and Wallenberg Clinical Scholars.

\section{Compliance with ethical standards}

\section{Conflicts of interest None.}

Ethical approval All procedures performed in studies involving human participants were in accordance with the ethical standards of the institutional and/or national research committee and with the 1964 Helsinki declaration and its later amendments or comparable ethical standards. For this type of study, formal consent is not required.

Open Access This article is distributed under the terms of the Creative Commons Attribution-NonCommercial 4.0 International License (http:// creativecommons.org/licenses/by-nc/4.0/), which permits any noncommercial use, distribution, and reproduction in any medium, provided you give appropriate credit to the original author(s) and the source, provide a link to the Creative Commons license, and indicate if changes were made.

\section{References}

1. Russell R, Graham G (2011) Bisphosphonates: the first 40 years. Bone 49:2-19. https://doi.org/10.1016/j.bone.2011.04.022

2. Lyles KW, Colón-Emeric CS, Magaziner JS et al (2007) Zoledronic acid and clinical fractures and mortality after hip fracture. N Engl J Med 357:1799-1809. https://doi.org/10.1056/NEJMoa074941

3. Black DM, Cummings SR, Karpf DB et al (1996) Randomised trial of effect of alendronate on risk of fracture in women with existing vertebral fractures. Lancet 348:1535-1541. https://doi.org/10.1016/ S0140-6736(96)07088-2

4. Cummings SR, Black DM, Thompson DE et al (1998) Effect of alendronate on risk of fracture in women with low bone density but without vertebral fractures: results from the Fracture Intervention Trial. JAMA 280:2077-2082. https://doi.org/10.1001/jama.280.24. 2077

5. Harris S, Watts N, Genant H et al (1999) Effects of risedronate treatment on vertebral and nonvertebral fractures in women with postmenopausal osteoporosis: a randomized controlled trial. JAMA 282:1344-1352. https://doi.org/10.1001/jama.282.14.1344

6. Reginster JY, Minne HW, Sorensen OH et al (2000) Randomized trial of the effects of risedronate on vertebral fractures in women with established postmenopausal osteoporosis. Osteoporos Int 11: 83-91 https://doi.org/00110083.198

7. Black DM, Delmas PD, Eastell R et al (2007) Once-yearly zoledronic acid for treatment of postmenopausal osteoporosis. N Engl J Med 356:1809-1822. https://doi.org/10.1056/NEJMoa067312

8. Reid IR, Horne AM, Mihov B et al (2018) Fracture prevention with zoledronate in older women with osteopenia. N Engl J Med 379: 2407-2416. https://doi.org/10.1056/NEJMoa1808082

9. Kranenburg G, Bartstra JW, Weijmans M et al (2016) Bisphosphonates for cardiovascular risk reduction: a systematic review and meta-analysis. Atherosclerosis 252:106-115. https:// doi.org/10.1016/j.atherosclerosis.2016.06.039

10. Bolland MJ, Gray AB, Gamble GD, Reid IR (2010) Effect of osteoporosis treatment on mortality: a meta-analysis. J Clin Endocrinol Metab 95:1174-1181. https://doi.org/10.1210/jc.2009-0852

11. Brozek W, Reichardt B, Zwerina J et al (2016) Antiresorptive therapy and risk of mortality and refracture in osteoporosis-related hip fracture: a nationwide study. Osteoporos Int 27:387-396. https:// doi.org/10.1007/s00198-015-3415-4

12. Sing CW, Wong AY, Kiel DP et al (2018) Association of alendronate and risk of cardiovascular events in patients with hip fracture. J Bone Miner Res 33:1422-1434. https://doi.org/10.1002/ jbmr.3448

13. Center JR, Bliuc D, Nguyen ND et al (2011) Osteoporosis medication and reduced mortality risk in elderly women and men. J Clin Endocrinol Metab 96:1006-1014. https://doi.org/10.1210/jc.20102730

14. Cameron ID, Chen JS, March LM et al (2010) Hip fracture causes excess mortality owing to cardiovascular and infectious disease in institutionalized older people: a prospective 5-year study. J Bone Miner Res 25:866-872. https://doi.org/10.1359/jbmr.091029

15. Beaupre LA, Morrish DW, Hanley DA et al (2011) Oral bisphosphonates are associated with reduced mortality after hip fracture. Osteoporos Int 22:983-991. https://doi.org/10.1007/ s00198-010-1411-2

16. Sambrook PN, Cameron ID, Chen JS et al (2011) Oral bisphosphonates are associated with reduced mortality in frail older people: a prospective five-year study. Osteoporos Int 22:25512556. https://doi.org/10.1007/s00198-010-1444-6

17. Nurmi-Lüthje I, Lüthje P, Kaukonen JP et al (2009) Post-fracture prescribed calcium and vitamin D supplements alone or, in females, with concomitant anti-osteoporotic drugs is associated with lower mortality in elderly hip fracture patients: a prospective analysis. Drugs Aging 26:409-421. https://doi.org/10.2165/00002512200926050-00005

18. Pazianas M, Abrahamsen B, Eiken PA et al (2012) Reduced colon cancer incidence and mortality in postmenopausal women treated with an oral bisphosphonate - Danish National Register Based Cohort Study. Osteoporos Int 23:2693-2701. https://doi.org/10. 1007/s00198-012-1902-4

19. Hartle JE, Tang X, Kirchner HL et al (2012) Bisphosphonate therapy, death, and cardiovascular events among female patients with CKD: a retrospective cohort study. Am J Kidney Dis 59:636-644. https://doi.org/10.1053/j.ajkd.2011.11.037

20. Lee P, Ng C, Slattery A et al (2016) Preadmission bisphosphonate and mortality in critically ill patients. J Clin Endocrinol Metab 101: 1945-1953. https://doi.org/10.1210/jc.2015-3467

21. Rennert G, Pinchev M, Gronich N et al (2017) Oral bisphosphonates and improved survival of breast cancer. Clin Cancer Res 23:1684-1689. https://doi.org/10.1158/1078-0432. CCR-16-0547

22. Goodbrand JA, Hughes LD, Cochrane L et al (2017) Association between bisphosphonate therapy and outcomes from rehabilitation in older people. Arch Gerontol Geriatr 70:195-200. https://doi.org/ 10.1016/j.archger.2017.01.017

23. Macmahon S, Collins R (2001) Reliable assessment of the effects of treatment on mortality and major morbidity, II: observational studies. Lancet 357:455-462

24. Bondo L, Eiken P, Abrahamsen B (2013) Analysis of the association between bisphosphonate treatment survival in Danish hip fracture patients - a nationwide register-based open cohort study. Osteoporos Int 24:245-252. https://doi.org/10.1007/s00198-0122024-8

25. Socialstyrelsen (2017) Täckningsgrader 2016. Stockholm [SE]

26. Rikshöft (2018) Rikshöft. https://rikshoft.se/registration/. Accessed 2 Nov 2018.

27. Ludvigsson JF, Andersson E, Ekbom A et al (2011) External review and validation of the Swedish national inpatient register. BMC Public Health 11:450. https://doi.org/10.1186/1471-2458-11-450

28. Barlow L, Westergren K, Holmberg L, Tälback M (2009) The completeness of the Swedish Cancer Register - a sample survey for year 1998. Acta Oncol (Madr) 48:27-33. https://doi.org/10.1080/ 02841860802247664 
29. Wettermark B, Hammar N, MichaelFored C et al (2007) The new Swedish Prescribed Drug Register-opportunities for pharmacoepidemiological research and experience from the first six months. Pharmacoepidemiol Drug Saf 16:726-735. https://doi. org/10.1002/pds. 1294

30. Brooke HL, Talbäck M, Hörnblad J et al (2017) The Swedish cause of death register. Eur J Epidemiol 32:765-773. https://doi.org/10. 1007/s10654-017-0316-1

31. Horwitz RI, Viscoli CM, Clemens JD, Sadock RT (1990) Developing improved observational methods for evaluating therapeutic effectiveness. Am J Med 89:630-638. https://doi.org/10. 1016/0002-9343(90)90182-D

32. Concato J, Shah N, Horwitz RI (2000) Randomized, controlled trials, observational studies, and the hierarchy of research designs. N Engl J Med 343:1887-1892. https://doi.org/10.1056/ NEJM200006223422507

33. Colón-Emeric CS, Mesenbrink P, Lyles KW et al (2010) Potential mediators of the mortality reduction with zoledronic acid after hip fracture. J Bone Miner Res 25:91-97. https://doi.org/10.1359/jbmr. 090704

34. Li YP, Propert KJ, Rosenbaum PR (2001) Balanced risk set matching. J Am Stat Assoc 96:870-882. https://doi.org/10.1198/ 016214501753208573

35. Lu B (2005) Propensity score matching with time-dependent covariates. Biometrics 61:721-728. https://doi.org/10.1111/j.1541-0420. 2005.00356.x

36. Suissa $\mathrm{S}$ (2007) Immortal time bias in observational studies of drug effects. Pharmacoepidemiol Drug Saf 16:241-249. https://doi.org/ 10.1002/pds. 1357

37. Austin PC (2011) An introduction to propensity score methods for reducing the effects of confounding in observational studies. Multivariate Behav Res 46:399-424. https://doi.org/10.1080/ 00273171.2011 .568786
38. Gayat E, Resche-Rigon M, Mary JY, Porcher R (2012) Propensity score applied to survival data analysis through proportional hazards models: a Monte Carlo study. Pharm Stat 11:222-229. https://doi. org/10.1002/pst.537

39. Freitag G, Lange S, Munk A (2006) Non-parametric assessment of non-inferiority with censored data. Stat Med 25:1201-1217. https:// doi.org/10.1002/sim.2444

40. Kanis JA, McCloskey EV, Johansson H et al (2010) Development and use of FRAX® in osteoporosis. Osteoporos Int 21:407-413. https://doi.org/10.1007/s00198-010-1253-y

41. Inderjeeth CA, Chan K, Kwan K, Lai M (2012) Time to onset of efficacy in fracture reduction with current anti-osteoporosis treatments. J Bone Miner Metab 30:493-503. https://doi.org/10.1007/ s00774-012-0349-1

42. Pocock SJ, Clayton TC, Altman DG (2002) Survival plots of timeto-event outcomes in clinical trials: good practice and pitfalls. Lancet 359:1686-1689. https://doi.org/10.1016/S0140-6736(02) 08594-X

43. Ray WA (2003) Evaluating medication effects outside of clinical trials: new-user designs. Am J Epidemiol 158:915-920. https://doi. org/10.1093/aje/kwg231

44. Socialstyrelsen (2014) Nationella riktlinjer - utvärdering: vård vid rörelseorganens sjukdomar 2014: indikatorer och underlag för bedömningar. Stockholm [SE]

45. Nahleh Z, Abrams J, Bhargaval A et al (2010) Outcome of patients with early breast cancer receiving nitrogen-containing bisphosphonates: a comparative analysis from the metropolitan detroit cancer surveillance system. Clin Breast Cancer 10:459-464. https://doi.org/10.3816/CBC.2010.n.060

Publisher's note Springer Nature remains neutral with regard to jurisdictional claims in published maps and institutional affiliations. 